\title{
ANALYSIS AND OPTIMIZATION OF CONNECTING TIE ROD ASSEMBLY IN AGRICULTURE APPLICATION
}

\author{
L. Natrayan ${ }^{1 *}$, E. Aravindaraj ${ }^{2}$, M.S. Santhosh ${ }^{3}$, M. Senthil Kumar ${ }^{1}$ \\ ${ }^{1}$ School of mechanical and Building sciences, VIT -Chennai, Tamilnadu, India. \\ ${ }^{2}$ Sri Manakula Vinayagar Engineering College, Mannadipet, 605107 Pudicherry, India. \\ ${ }^{3}$ Selvam College of Technology, Salem Road (NH 7), Pappinaickenpatti, Namakkal, 637003 Tamil Nadu, India.
}

This is an open access article distributed under the Creative Commons Attribution License, which permits unrestricted use, distribution, and reproduction in any medium, provided the original work is properly cited.

\section{ARTICLE DETAILS}

\section{Article History:}

Received 27 September 2018 Accepted 25 November 2018 Available online 27 February 2019

\begin{abstract}
The tie rod ensures the safety of vehicle on both impact and vibration perspective also plays one of the major roles in connecting primary parts of automobile and steering mechanism. Its end is an indication system of vehicle alignment. The tie rod end maintains the proper adjustment access of the wheel as well as indirectly limits the inner and outer edge wear of tires. Hence the appropriate functioning of tie rod assembly system is essential for the automobile system (steering and suspension). Today's competitive world needs advanced technology with effective cost. This results in the mutation of conventional technology or method according to present requirements. Most of the automobile and commercial product manufacturing industries are in the obsession to make and launch the economical product with the limited time span. The engineers from various domains are deliberately designing unique products, which possess simple manufacturing process, lower cost of manufacturing and very minimum time consumption. The proposed design and analysis focus on general tie rod assembly functioning of the tractor which fails on the overload applications. Firstly, old tie rod design and materials used for effective agriculture applications were studied and the mutated design with various stresses and deformation characteristics under critical loading conditions are investigated using ANSYS software.
\end{abstract}

\section{KEYWORDS}

Tie rod assembly, Deformation, Clamp structure, ANSYS, Front axle, Agriculture application.

\section{INTRODUCTION}

Tie rod ends support thru the steering of a vehicle and variety it possible to capture a tire. These devices occur in pairs on each tire. This sanctions for cornering and angling of the tire minus affecting too much torque on the trundle nope staple how deep the seizure [1]. Tie-rod is certain as driving adherent for slanting the panel (along with panel mounting frame) from horizontal to vertical position and vice versa. In principal, tie-rod will have essential coupler with nail rods on sides, one through left hand thread and another through right hand thread [2]. The coupler has identical threads to put up these eased tie rods [3]. On spinning the coupler is turned, together the rods will spread or withdraw based on the trend of rotation of coupler. The ends of the rods are moreover eye or fork expiration type [4].

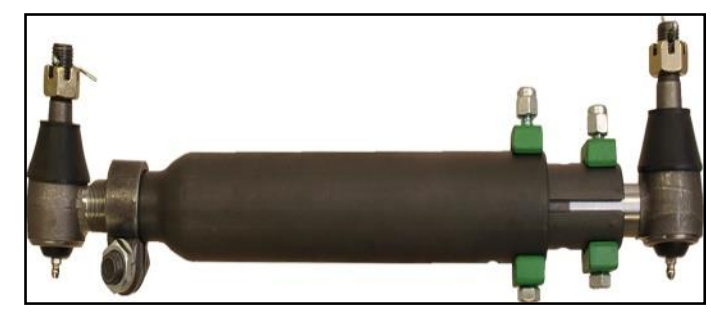

Figure 1: Adjustable tie rod

Lighter connecting rods help to decrease lead caused by forces of inertia in engine as it does not require big balancing weight on crankshaft. Application of metal matrix composite enables safety increase and advances that leads to effective use of fuel and to obtain high engine power. Honda Company had already started the manufacturing of aluminium connecting rods reinforced with steel continuous fibers [5]. By carrying out these modifications to engine elements will result in effective reduction of weight, increase of durability of particular part, will lead to decrease of overall engine weight, improvement in its traction parameters, economy and ecological conditions such as reduction in fuel consumption and emission of harmful substances into atmosphere. A typical tie rod in automotive system is made up of an inner and outer end which transmits motion from the steering centre link or rack gear to the steering knuckle which in turn caused the wheels to rotate as shown in Figure 1.

The outer tie rod end is connected to an adjusting sleeve which allows the length of the tie rod to be adjusted when the car is in operation. This adjustment is useful while trying to set a car's alignment angle [6,7]. A sound tie rod plays a significant role in a car steering system performance as well as driver and passenger's safety, but the uncertainty about a typical tie rod is based on its longevity. Like most automobile components, tie rod does not easily go bad on their own, but depending on the loading conditions they are exposed, may result in wear and tear [8]. K. Sudershan kumar and his collogues, described modeling and analysis of Connecting rod [9]. In his project carbon steel connecting rod is replaced by aluminium boron carbide connecting rod.

Aluminium boron carbide is found to have working factory of safety is nearer to theoretical factory of safety, to increase the stiffness by $48.55 \%$ and to reduce stress by $10.35 \%$. Vivek. C. A group researchers dealt with the stress analysis of connecting rod by finite element method using pro-e wild fire 4.0 and ansys work bench 11.0 software [10]. And concluded that the stress induced in the small end of the connecting rod are greater than the stresses induced at the bigger end, therefore the chances of failure of the connecting rod may be at the fillet section of both end. In other study, they have performed the static FEA of the connecting rod using the software and said optimization was performed to reduce weight [11]. Weight can be reduced by changing the material of the current forged steel connecting rod to crackable forged steel (C70). And the software gives a view of stress distribution in the whole connecting rod which gives the information that which parts are to be hardened or given attention during 
manufacturing stage. In a paper of dynamic simulation was conducted on a connecting rod made of aluminium alloy using FEA [12]. In this analysis of connecting rod were performed under dynamic load for stress analysis and optimization.

Dynamic load analysis was performed to determine the in-service loading of the connecting rod and FEA was conducted to find the stress at critical locations. However, tie rods can last for relatively long period of time and most drivers may rarely replace them at all, but their longevity can be hampered as a result of certain driving conditions such as potholes, speed bumps or minor accident which may affect the tie rod performance. Due to its relevance in automobile systems and its high usage, routine inspection is recommended to prevent the occurrence of unforeseen accidents, and if replacement is required at the end of each inspection, both left and right set as installed on the front suspension of a vehicle is recommended and a complete four wheel balancing and alignment should be carried out at the same time to ensure safety of the driver and passenger (s) on highway [13].

Failure to carry out routine checks on the tie rod may result in certain warning signs such as incidents were the car pulls to one side while driving or when brake is applied. Also, bad tie rods can negatively affect a car's front and end alignment which may result in uneven wear of the inner and outer edge of a vehicle tire. Moreover, as tie rod ends are subjected to wear, it can slacken and loose gradually thereby, resulting in failure which may affect the driver's ability to steer and control the car [14]. One of the most easily observed signs of a faulty tie rod can be squeaking noises or knocking sound from the front end of the car when the steering wheel is turned to a certain angle. Finally, if the car has been exposed to any unsafe road conditions, or unusual contact with the front wheels such as driving across a big stone it may be ideal to subject the tie rod to inspection as faulty tie rods can also be responsible for instability of the steering wheel, vibration, looseness or a wandering or erratic feel on the steering wheel.

\subsection{Adjustable front axle with adjustable Tie rod}

This origination relays to a tractor and more specifically to a regulating front axle for a row crop farm tractor. In farm tractors of the row produce type it is crucial to afford for widening and narrowing the stamp of the ambition wheels where a three-wheel tractor is fretful [15]. A four-wheel rumpus crop tractor requires that both front and rear wheels be adjustable squarely, in directive to travel between the plants in the rows [16]. The peak common scheme of varying the width of the wheel tread on ruckus crop tractors currently is to dispose the wheels hubs and tire rims in such routine that by reversing the wheels in relative to the hubs the stamp may be amplified or narrowed [17]. While the development above described may perform to be a artless earnings of amending the stride of the wheels of the tractor, however such amending mechanism fills a long desired want of stingily and easily altering the width of the tread of façade wheels of row crop tractors [18].

\section{EN8 CARBON STEEL MATERIAL IS SELECTED FOR THIS DESIGN}

EN8 is typically abounding organic but can be supplied to edict in the stabilized or finally heat salted (appeased and tempered to "Q" or "R" properties for off-putting ruling subdivisions up to $63 \mathrm{~mm}$ ), which is ample for a widespread range of applications. EN8 is suitable for the assembly of quantities such as general-tenacity axles and shafts, gears, bolts and studs [19]. It can be auxiliary hardboiled typically to 50-55 HRC by initiation processes, producing modules with enriched wear resistance. For such tenders the use of $E N 8 D(080 \mathrm{~A} 42)$ is prudent. EN8 in its heat frozen rehearses possesses virtuous homogenous metallurgical structures, philanthropic unfailing machining properties [20]. Virtuous heat treatment grades on segments grander than $63 \mathrm{~mm}$ may still be attainable, but it should be illustrious that a fall-off in mechanical properties would be superficial potential the epicenter of the bar [21]. Table 1 gives mechanical properties of material.

Table 1: Material Properties

\begin{tabular}{|c|c|c|}
\hline S.No & Material & Yield Strength $\mathrm{N} / \mathrm{mm}^{2}$ \\
\hline 1 & EN8 & 465 \\
\hline 2 & EN8D & 443 \\
\hline 3 & EN5D & 451 \\
\hline 4 & EN5C & 438 \\
\hline
\end{tabular}

Cost comparisons

$\begin{array}{ll}\text { Cost of } 1 \mathrm{~kg} \text { EN } 8 & =\text { Rs. } 36.42 \\ \text { Cost of } 1 \mathrm{~kg} \mathrm{EN} \mathrm{8D} & =\text { Rs.37.80 } \\ \text { Cost of } 1 \mathrm{~kg} \text { EN 5D } & =\text { Rs.40.56 } \\ \text { Cost of } 1 \mathrm{~kg} \text { EN 5C } & =\text { Rs.39.53 }\end{array}$

When compared to mechanical property and cost EN8 is the best one for design the product and economical one [22].

\section{EXISTING THRU-HOLE DESIGN PARTS}

The previous research papers are useful for deciding the analysis strategy. There were numerous conference papers, reference manuals, book by Robert cook Concepts and applications of FEA will be helpful for the project. From some of the research work it is being observed that the existing thru hole design model.

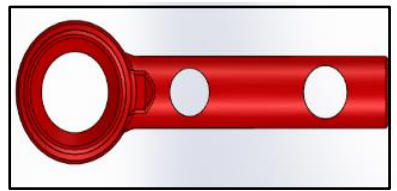

Figure 2: Socket

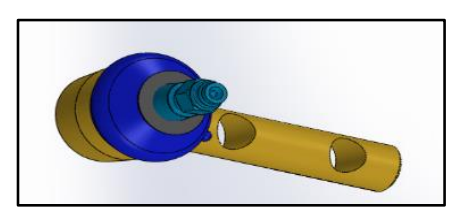

Figure 3: Radial ball joint
The existing geometrical model is created as a solid works 2016 software and analysis in Ansys Workbench, The geometrical model constitutes of the socket (figure 2), radial ball joint (figure 3), tube (figure 4) and axle ball joint (figure 5). While neglecting the parts that are thought as negligible in the analysis. Figure 6 shows that existing tie rod design using solid works software.

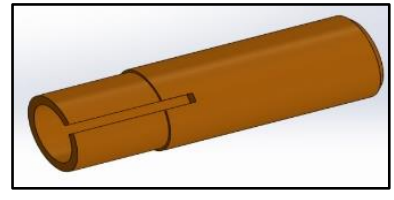

Figure 4: Tube

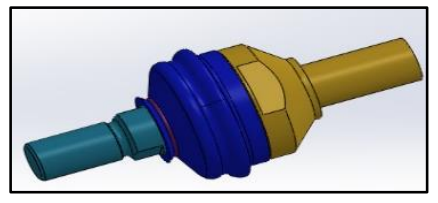

Figure 5: Axle ball joint

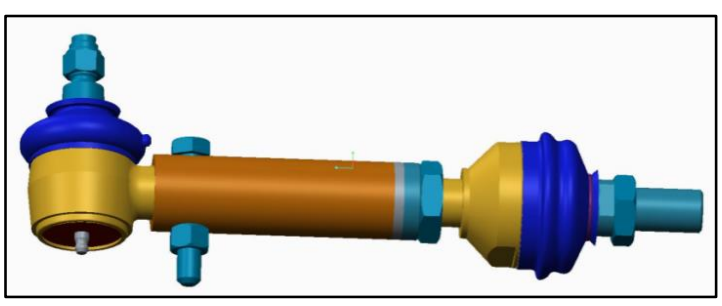

Figure 6: Existing Tie rod design

\section{PROBLEM IDENTIFICATION}

In the existing design nut and bolt joints are used to connect the socket and tube, so it can't withstand more compressive load and tensile load. It leads to bend which causes breakage in the tie rod. Also, the thru-hole design is applicable to load only below $2000 \mathrm{~kg}$ and when the load increases the tie rod bends. So it can't withstand more than $2500 \mathrm{~kg}$ tensile load and compressive load.

\section{PROPOSED NEW DESIGN}

The tie rod is continuously under random loading there can be more chances of developing the cracks at the critical areas and chances of failure. Also the manufacturing process of this existing design is critical and time consuming. Hence it is necessary to make the design simple and cost effective such that it gives overall effectiveness in terms of weight, cost, load carrying capacity and easy of manufacturing process. The main task in this study is to find the critical buckling load for the existing design. Observe the deformation and stresses induced in the Tie rod. Set up the benchmark for the proposed design. 


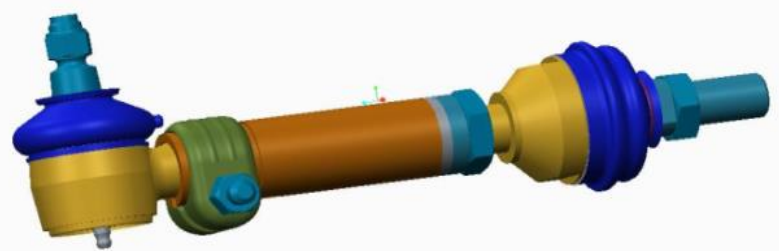

Figure 7: Proposed new design

Figure 7 shows proposed new connecting tie rod design, thru-hole clamped design used to connect the tube and socket. Because of groove and clamp withstands more compressive and tensile load compare to exiting design.

\subsection{Existing model tie rod analysis}

The existing tie rod model has carried out static analysis using EN8 carbon steel material, while applied the load upto $2000 \mathrm{~kg}$ in exiting model, it's can't shows any deformation. Figure 8 and 9 shows that thru-hole design applicable only below $2000 \mathrm{~kg}$ load.

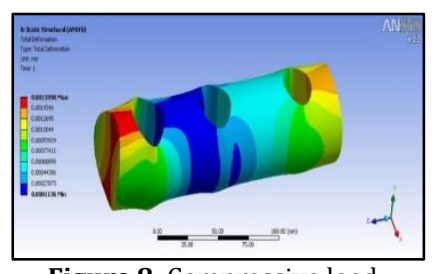

Figure 8: Compressive load

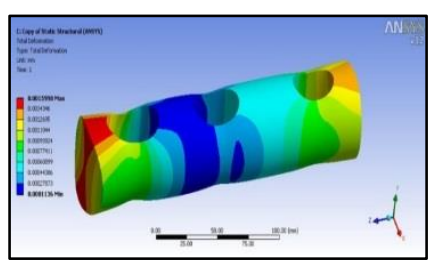

Figure 9: Tensile load
Increasing the tensile and compression load upto $2500 \mathrm{~kg}$, existing model tie rod getting failure and its goes to deformation. Figure 10 and 11 shows failure action of tie rod during $2500 \mathrm{~kg}$ load.

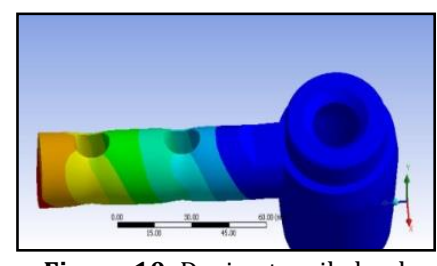

Figure 10: During tensile load

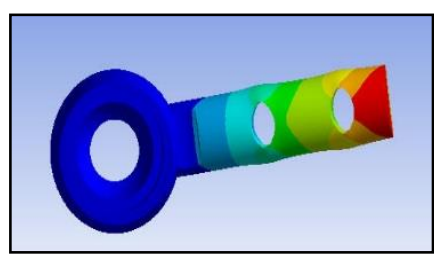

Figure 11: During compressive

\subsection{Sample Groove design with hollow construction (Existing Design)}

When compared to thru hole this groove design withstands more load during compression load. From the Figure 12 groove design with hollow construction can't withstand more than $2500 \mathrm{~kg}$ of compressive load. So, this designs also not suitable for the tie rod.

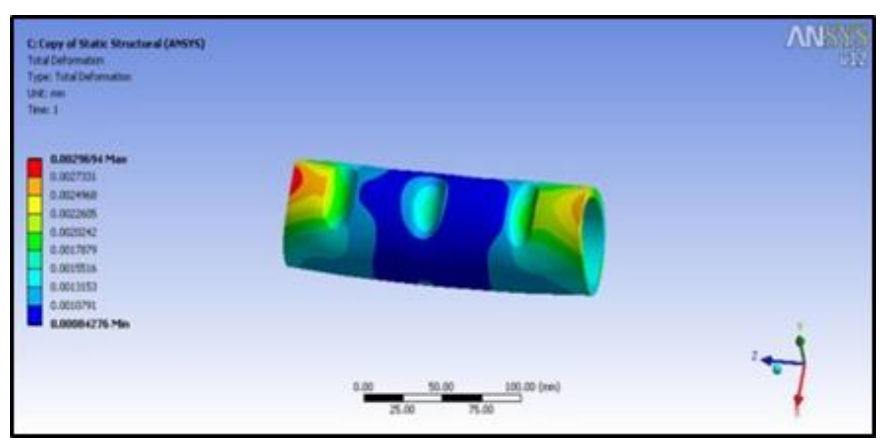

Figure 12: Compressive load test for hollow Groove design

\section{PROPOSED NEW DESIGN ANALYSIS}

\subsection{Sample Solid groove design}

The solid groove design has analysis using EN8 carbon steel in Figure 13 and 14 . Hence, Solid groove design withstands more loads when compared to both hollow groove and thru-hole design. It can't withstand up to $3500 \mathrm{~kg}$ of compressive load \& tensile load. So this the suitable design for the adjustable tie rod.

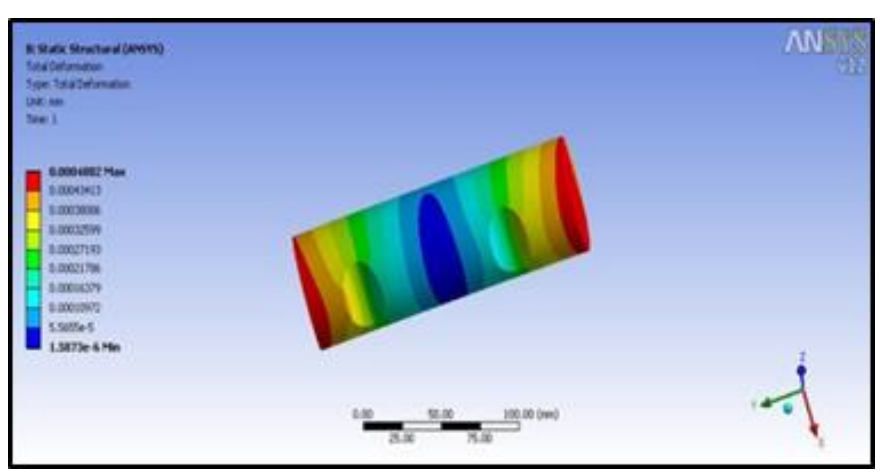

Figure 13: Compressive load Test on Solid groove design

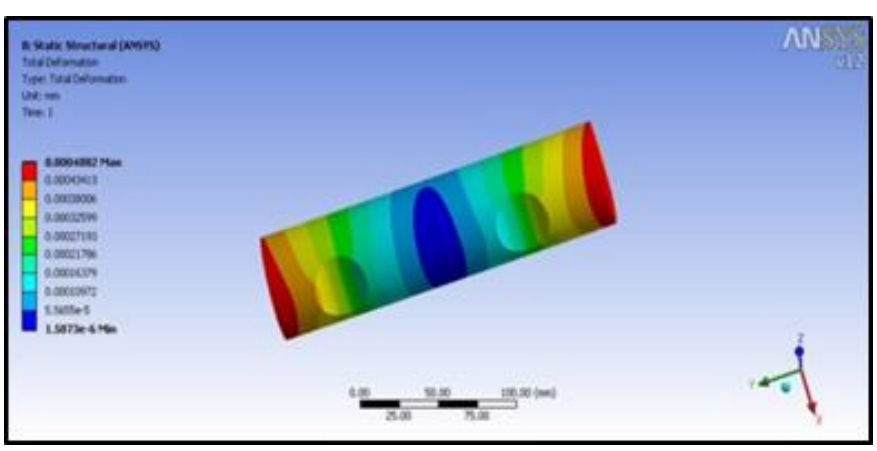

Figure 14: Tensile load Test Solid groove design

6.2 Tensile and compression Load Analyses of Adjustable Tie Rod

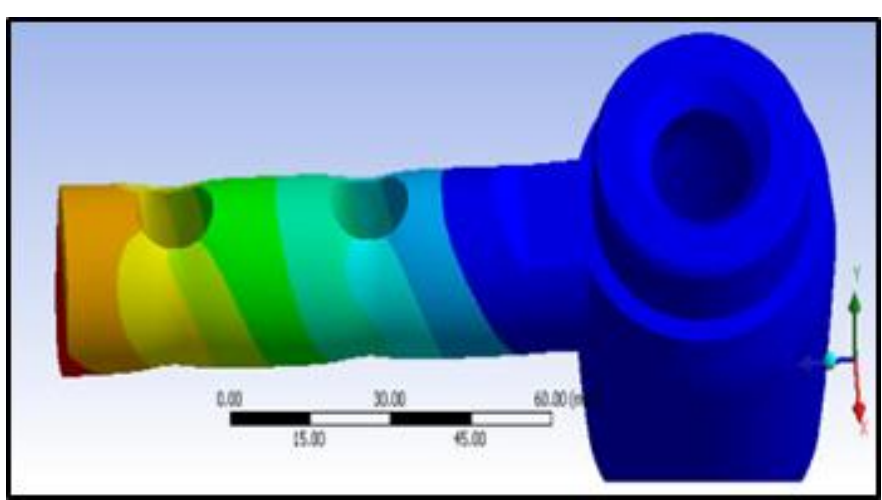

Figure 15: Thru Hole Design

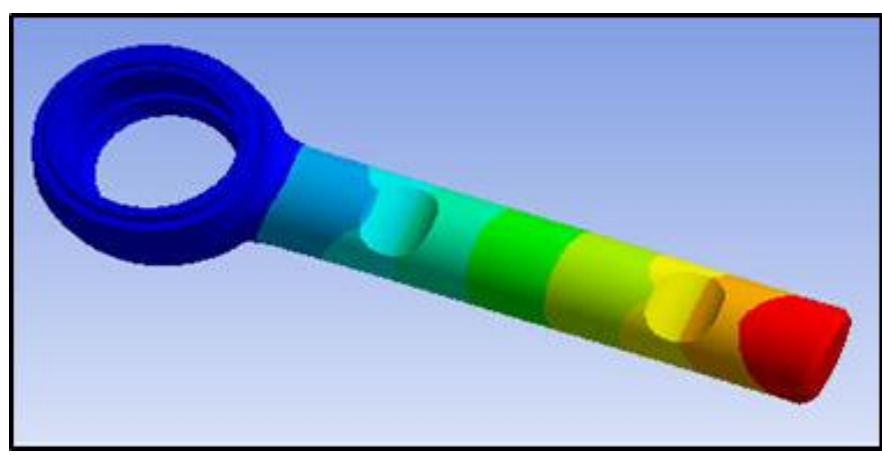

Figure 16: Clamped Design

Above figure 15 and 16 shows the thru hole design failed to withstand the $3000 \mathrm{~kg}$ tensile load, but grooved design can withstand more load when compared to thru hole design in tie rod. 


\section{COMPARISON OF ANALYSIS RESULT}

Table 2: Socket with through hole

\begin{tabular}{|l|l|l|l|}
\hline S.No & $\begin{array}{l}\text { Load in } \\
\text { KGF }\end{array}$ & $\begin{array}{l}\text { Max stress } \\
\text { in N/mm }\end{array}$ & FOS \\
\hline 1 & 2500 & 364.50 & 0.76818 \\
\hline 2 & 3000 & 437.4 & 0.64015 \\
\hline 3 & 4000 & 583.3 & 0.48003 \\
\hline
\end{tabular}

Table 3: Socket with groove

\begin{tabular}{|l|l|l|l|}
\hline S.No & $\begin{array}{l}\text { Load in } \\
\text { KGF }\end{array}$ & $\begin{array}{l}\text { Max stress } \\
\text { in N/mm }\end{array}$ & FOS \\
\hline 1 & 2500 & 151.7 & 1.85 \\
\hline 2 & 3000 & 182.4 & 1.54 \\
\hline 3 & 4000 & 243.2 & 1.15 \\
\hline
\end{tabular}

From the table 2 and 3 shows static analysis results for existing and proposed new design using EN8 Carbon steel. From the result maximum stress has acted on the through hole design and proposed design has less deformation is obtained compare to exiting tie road model. Tie rods are merely subjected with more compressive forces. From the above analysis shows that proposed design has more damping capacity and can withstand more compressive forces. This is due to because of carbon flake distribution in the material. Carbon flake distribution is better in EN8 carbon steel.

\section{BUCKLING OF THIN CYLINDRICAL SHELLS SUBJECT TO AXIAL LOADS}

Clarifications of Donnell's eight order differential equation provides the innumerable buckling approaches of a thin cylinder underneath compression. But this analysis, which is in harmony with the slight refraction theory bounces much sophisticated morals than shown from tryouts [23]. So it is habitual to find the precarious buckling load for countless erections which are cylindrical in silhouette from pre-existing design cambers where perilous buckling load FCR is intrigued alongside the ratio $\mathrm{R} / \mathrm{t}$, where $\mathrm{R}$ is the radius and $\mathrm{t}$ is the thickness of the cylinder for innumerable values of $L / R, L$ the length of the cylinder. If cut-outs are modern in the cylinder, life-threatening buckling loads as well as prebuckling slants will be exaggerated [24].

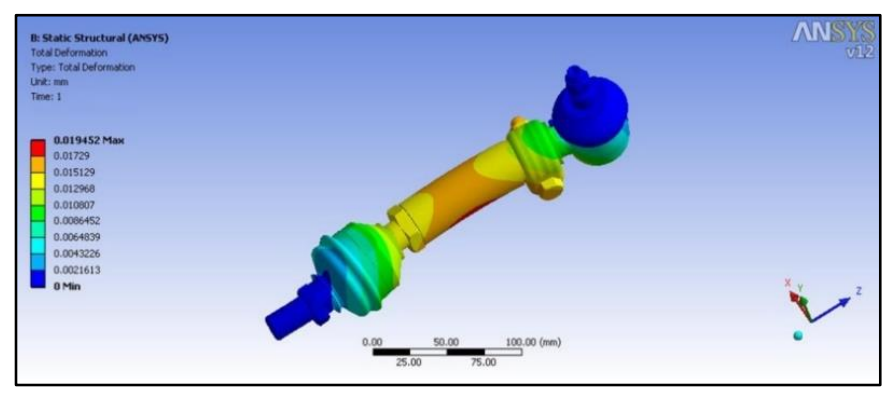

Figure 16: Buckling load test on adjustable connecting tie rod

Examination of this formula reveals the following interesting facts with regard to the load-bearing ability of slender columns.

\subsection{Bending or buckling load}

Bending load in both ends hinged is given by $(\mathrm{BL})=3.14 * 3.14 * \mathrm{E} * \mathrm{I} / \mathrm{L} * \mathrm{~L}$ Where, E-Young's modulus, I-Moment of inertia, L-Length of the tie rod. According to both ends hinged condition the length of the rod is same Otherwise the length will vary.

\section{$\mathrm{I}=3.14 /\left[\mathrm{D}^{*} \mathrm{D}^{*} \mathrm{D}^{*} \mathrm{D}-\mathrm{d} * \mathrm{~d}^{*} \mathrm{~d}^{*} \mathrm{~d}\right]$}

Connecting Tie rod dimensions $\mathrm{OD}=30 \mathrm{~mm}, \mathrm{ID}=22.5 \mathrm{~mm}$, Moment of inertia $\quad I=27166.44$

\subsection{Bending load of proposed new design}

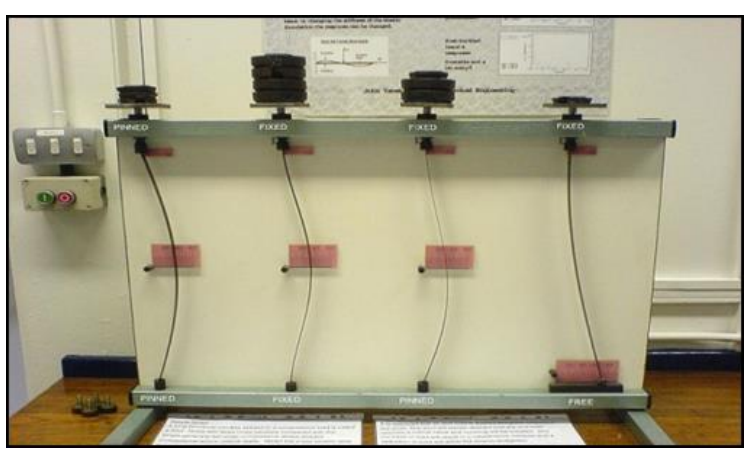

Figure 17: Bending load calculation

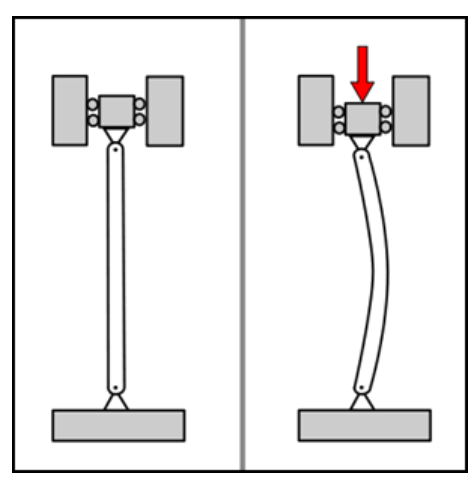

Figure 18: Failure of struts or columns

$\mathrm{BL}=3.14 * 3.14 * 6250 * 27166.44 / 52900$

$\mathrm{BL}=31.6 \mathrm{KN}$

Fig 17 shows that bending load calculation for proposed design, it's enough for the rod to withstand compressive and tensile load. When compared to previous design clamped design having more bending loads capacity. Previous design bending load is $25.86 \mathrm{KN}$. This design bending load is $31.6 \mathrm{KN}$, and so this design is good when compared to existing design

\section{CONCLUSION}

Existing thru hole design of connecting tie rod has been mutated with clamp groove made up of EN8 carbon steel material and investigated in this proposed study. Existing and proposed model has done in solid works software in the form of a multi-body system, after that solid structure was produced where all interconnected essentials supposed to be perfectly inflexible, and in absolute stage of taxing finite element analysis was executed consuming Ansys software package. From the accessible results we can arrange that the dissemination of deformation and stress do not overdo the yield strength value and that there are neither indemnities nor failure of Tie rod. The load 2000kg has applied in exiting model, it's can't shows any deformation. While increasing the load upto $2500 \mathrm{~kg}$, thru-hole design getting bend because it cannot withstand the over load, so that thru hole design model has applicable only below $2000 \mathrm{~kg}$ load. The maximum load of $4000 \mathrm{kgf}$ has acting on thru hole and groove design model. since, the thru hole design results shows stress has act $583.3 \mathrm{~N} / \mathrm{mm}^{2}$, Factor of safety is 0.48003 , and Groove design model results show that stress has act $243.2 \mathrm{~N} / \mathrm{mm}^{2}$ and Factor of safety is 1.15 . Thru-hole design bending load is $25.86 \mathrm{KN}$ and Clamp design bending load is $31.6 \mathrm{KN}$. The static analysis portrays that mutated tie rod model shows lower deformation than existing design also, the critical buckling load of proposed design is comparatively higher than conventional design. It has approximately $25 \%$ more buckling load carrying capacity. We conclude from the obtained results that stress and deformation will not cross maximum yield strength of tie rod assembly there is either minor damages or minimum possibility of failure in new groove design assembly. These results clearly depict that the proposed output is preferably suitable for Agricultural and commercial tractors. 


\section{REFERENCES}

[1] Senniappan, M., More, R., Bhide, S., Gowda, S. 2016. Optimization of Commercial Vehicle's Steering Tie Rod Arm Design Based on Strain Life Approach. SAE Technical Paper, 1, 0381. DOI: 10.4271/2016-01-0381.

[2] Natrayan, L., Kumar, M.S. 2018. Study on Squeeze Casting of Aluminum Matrix Composites-A Review. Advanced Manufacturing and Materials Science. Springer, Cham, 75-83. DOI: 10.1007/978-3-319-76276-0_8.

[3] Kulkarni, U., Gowda, M., Venna, H. 2016. Effect of Tie Rod Length Variation on Bump Steer. SAE Technical Paper, 28, 02-01. DOI :10.4271/2016-28-0201.

[4] Duan, W., Joshi, S. 2011. Failure analysis of threaded connections in large-scale steel tie rods. Engineering failure analysis, 18 (8), 2008-2018. DOI: 10.1016/j.engfailanal.2011.06.002.

[5] Falah, A.H., Alfares, M.A., Elkholy, A.H. 2006. Failure investigation of a tie rod end of an automobile steering System. Mechanical Engineering Department, Kuwait University, Safat 13060, Kuwait.

[6] Manik, A.P., Chavan, D.S., Kavade, M.V., Umesh, S.G. 2013. FEA of Tie Rod of Steering System of Car. International Journal of Application or Innovation in Engineering and Management, 2 (5), 2319-4847.

[7] Kim, H., Seo, M., Bae, W. 2002. A Study of the Manufacturing of Tie Rod Ends with Casting/Forging Process. Journal of Material Processing Technology, 125, 471-476.

[8] Vegi, L.K., Vegi, V.G. 2002. Design and Analysis of connecting rod using Forged Steel. International Journal of Scientific and Engineering Research, 32 (4-6), 2081-2090.

[9] Kumar, K.S., Reddy, K.T., Hussan, S.A. 2012. Modelling and analysis of two-Wheeler connecting rod. International Journal of Modern Engineering Research, 2 (5), 3367-3371.

[10] Pathade, V.C., Patle, B., Ingale, A.N. 2012. Stress Analysis of I.C. Engine Connecting Rod by FEM. International Journal of Engineering and Innovative Technology, 1 (3), 12-15.

[11] Sharma1, P.K., Rajendra, R.B. 2012. Fatigue analysis and Optimization of Connecting rod using finite element analysis. International Journal of advance research in Science and Engineering, 1 (I), 3367- 3371.

[12] Bansal, R. 2013. Dynamic simulation of connecting rod made of aluminium alloy using finite element analysis approach. IOSR Journal of Mechanical and Civil Engineering, 5 (2), 01-05.

[13] Mohamed, D., Elsayed, A.Y., Nassar, K. 2018. Design and constructability of a novel funicular arched steel truss false work. Journal of construction engineering and management, 144.3: 04018002. DOI:
10.1061/(ASCE)C0.1943-7862.0001449

[14] Natrayan, L., Kumar, M.S., Palanikumar, K. 2018. Optimization of squeeze cast process parameters on mechanical properties of $\mathrm{Al}_{2} \mathrm{O}_{3} / \mathrm{SiC}$ reinforced hybrid metal matrix composites using taguchi technique. Materials Research Express, 5, 066-516. DOI: 10.1088/20531591/aac873.

[15] Repgen, B. 1998. Optimized Connecting Rods to Enable Higher Engine Performance and Cost Reduction. SAE Technical Paper Series, Paper No. 980882.

[16] Santhosh, M.S., Sasikumar, R., Natrayan, L., Kumar, M.S., Elango, V., Vanmathi, M. 2018. Investigation of mechanical and electrical properties of kevlar/E-glass and basalt/E-glass reinforced hybrid Composites. International Journal of Mechanical and Production Engineering Research and Development, 8 (3), 591-598.

[17] Park, Y.C., Baek, S.K., Seo, B.K., Kim, J.K., Lee, K.H. 2014. Lightweight design of an outer tie rod for an electrical vehicle. Journal of applied mathematics, Article ID 942645, 6 pages. DOI:10.1155/2014/942645.

[18] Wayal, S.U., Katratwar, T. 2016. Transient Dynamic Analysis for Optimization of Tie Rod Using FEM. International Journal of Scientific and Research Publications, 6 (9), 263-267.

[19] Yıldız, B.S., Yıldız, A.R. 2018. Comparison of grey wolf, whale, water cycle, ant lion and sine-cosine algorithms for the optimization of a vehicle engine connecting rod. Materials Testing, 60 (3), 311-315. DOI:10.3139/120.111153.

[20] Kim, J.K., Kim, Y.J., Yang, W.H., Park, Y.C., Lee, K.H. 2011. Structural design of an outer tie rod for a passenger car. International Journal of Automotive Technology, 12 (3), 375-381. DOI: $10.1007 / \mathrm{s} 12239-011-0044-6$.

[21] Megharaj, C.E., Nagaraj, P.M., Pasha, K.J. 2016. Design and analysis of a forging die for manufacturing of multiple connecting rods. In IOP Conference Series: Materials Science and Engineering, 149 (1), 012-145.

[22] Anusha, B., Reddy, C.V.B. 2013. Modelling and Analysis of TwoWheeler Connecting Rod by Using Ansys. IOSR Journal of Mechanical and Civil Engineering (IOSRJMCE), 6 (5), 83-87.

[23] Chavan, P.M., Patnaik, M.M.M. 2014. Performance evaluation of passenger car tie rod using numerical and theoretical approach with different materials. International Journal of Research in Engineering and Technology, 3 (8), 92-100.

[24] Mungi, S. 2015. Performance Optimization of Tie rod using FEAIJERD. International Journal of Engineering Research and Development, 11 (3), 27-33. 